\title{
Inverted internal limiting membrane-flap technique for large macular hole: a microperimetric study
}

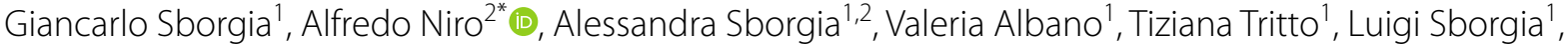 \\ Valentina Pastore ${ }^{1}$, Rossella Donghia ${ }^{3}$, Ermete Giancipoli ${ }^{4}$, Nicola Recchimurzo ${ }^{1}$, Francesco Boscia ${ }^{4}$ \\ and Giovanni Alessio ${ }^{1}$
}

\begin{abstract}
Background: Inverted Internal Limiting Membrane (ILM)-flap technique would seem to lead to higher closure rate and better visual acuity than traditional procedure with ILM peeling for the treatment of large macular hole (LMH). Visual acuity recovery does not reveal many other functional changes related to surgical approach. Our purpose was to evaluate macular function and morphology over a 1-year follow-up after inverted ILM-flap technique for LMH by using microperimetry in order to predict visual prognosis.

Methods: This study was a prospective unrandomized single-center study. 23 eyes of 22 patients with idiopathic $\mathrm{LMH}$, with a minimum diameter ranging from 400 to $1000 \mu \mathrm{m}$, were included. All patients underwent vitrectomy with inverted ILM-flap technique and gas tamponade. We analyzed macular hole closure rate and functional outcomes including best-corrected visual acuity (BCVA), macular sensitivity (MS) at central $12^{\circ}$ and central macular sensitivity (CMS) at central $4^{\circ}$, and fixation behavior as bivariate contour ellipse area (BCEA, degrees ${ }^{2}$ ) at $68 \%, 95 \%$, and $99 \%$ of fixation points measured by microperimeter, over a follow-up of 12 months.

Results: The macular hole closure rate was 98\%. The BCVA improved from 20/230 (Logmar, 1.06 \pm 0.34 ) to 20/59 (logMar, $0.47 \pm 0.45$ ) at last follow-up ( $p<0.001$ ). Retinal sensitivity and BCEA significantly improved (MS, $p=0.001$; CMS, $p<0.0001 ; B C E A: 68 \%, p<0.01 ; 95 \%, p<0.01 ; 99 \%, p=0.001)$. Multiple stepwise regression analysis showed the final $B C V A$ was significantly associated with macular hole size $(\beta=0.002, p=0.03)$, preoperative $M S(\beta=-0.06, p=0.001)$ and $B C E A$ at $95 \%$ and $99 \%$ of fixation points $(\beta=-0.12, p=0.01 ; \beta=0.06, p=0.01)$.

Conclusions: Inverted ILM-flap technique for $\mathrm{LMH}$ results in good morphologic and functional outcomes. Macular hole size and microperimetric parameters as preoperative MS and BCEA have a predictive role on post-surgical visual acuity.
\end{abstract}

Keywords: Large macular hole, Inverted ILM-flap, Microperimetry, Retinal sensitivity, Fixation behaviour

\section{Background}

Idiopathic full-thickness macular hole is an important cause of central vision impairment and metamorphopsia in elderly people [1]. The conventional procedure for macular hole surgery consists of internal limiting

\footnotetext{
${ }^{*}$ Correspondence: alfred.nir@tiscali.it

2 Eye Clinic, Hospital "S. G. MOSCATI", ASL TA, Via Per Martina Franca,

74010 Statte, Taranto, Italy

Full list of author information is available at the end of the article
}

membrane (ILM) peeling and air or gas tamponade [25]. In cases with large macular hole (LMH) the anatomical success rate, as the closing of the hole, is as low as $40 \%$ to $80 \%$ using conventional procedure [6-8]. Michalewska et al., in a prospective trial, found that anatomical closure rate was higher using a novel technique of inverted ILMflap technique (98\%) compared to traditional procedure with ILM peeling (88\%) for the treatment of LMH. In the same study post-operative visual acuity was significantly higher using the new technique [9]. Several papers have

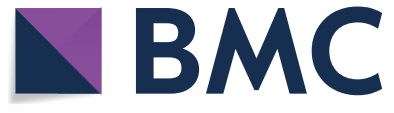

(c) The Author(s) 2019. This article is distributed under the terms of the Creative Commons Attribution 4.0 International License (http://creativecommons.org/licenses/by/4.0/), which permits unrestricted use, distribution, and reproduction in any medium, provided you give appropriate credit to the original author(s) and the source, provide a link to the Creative Commons license, and indicate if changes were made. The Creative Commons Public Domain Dedication waiver (http://creativecommons.org/ publicdomain/zero/1.0/) applies to the data made available in this article, unless otherwise stated. 
suggested that inverted ILM-flap technique may be better for the treatment of LMHs considering morphologic and functional outcomes [10-13]. Despite high closure rate and visual acuity recovery, functional changes after macular hole surgery are really complex. Visual acuity recovery does not reveal many other functional changes related to macular pathologies and surgical manipulations. So central retinal sensitivity and fixation behavior analysis using microperimeter can provide further objective and quantitative informations about macular function, enabling to analyse exact correlation between macular disease, as age-related maculopathy, diabetic macular oedema, macular oedema after vein occlusion, idiopathic epiretinal membrane, central serous chorioretinopathy, inflammatory macular oedema and macular dystrophy, and corresponding function, in assessment of natural history and treatment outcomes [14-22]. Previous papers reported a significant improvement of retinal sensitivity and fixation properties after traditional ILM peeling for macular hole [23-27], revealing a predictive role of preoperative macular hole feature and microperimetric parameters on visual recovery [27-30]. The aim of this study was to evaluate morphologic and functional outcomes after vitrectomy with inverted ILM-flap technique for LMH by using microperimetry in order to predict visual prognosis.

\section{Methods}

In this prospective study we analysed 22 eyes of 23 consecutive patients with idiopathic LMH (diameter $>400 \mu$ ) who underwent 27 -gauge vitrectomy with inverted ILMflap technique. In all cases surgery was performed at the Eye Clinic of University of Bari, Bari, Italy, between April 2017 to April 2018. All the surgeries were performed by the same well-experienced retinal specialist (GS). Patients with amblyopia, severe refractive defect, corneal opacity, glaucoma or ocular hypertension, prior vitreoretinal surgery, proliferative diabetic retinopathy, retinal vascular disease, age-related macular degeneration, traumatic or myopic macular hole, retinal detachment due to macular hole, and minimum diameter of macular hole $>1500 \mu \mathrm{m}$ were excluded. All patients underwent a complete ophthalmic examination, including best corrected visual acuity (BCVA) measurement (with ETDRS chart), slit lamp biomicroscopy, intraocular pressure (IOP) test, indirect ophthalmoscopy, optical coherence tomography (OCT) and microperimetry. BCVA was recorded as Snellen visual acuity and converted to logarithm of minimal angle of resolution (logMar) units for statistical analysis. Macular sensitivity and fixation stability were evaluated by MP-1 microperimeter (MP-1, Nidek Technologies, Padova, Italy). The MP-1 provides a $45^{\circ}$ non-mydriatic view of the fundus with automated correction for eye movements. We performed microperimetry under room dim light condition. MP-1 uses a background luminance of $10 \mathrm{~cd} / \mathrm{m}^{2}$, maximum stimulus intensity of $125 \mathrm{~cd} / \mathrm{m}^{2}$, stimulus size of 0.11-1.73 degrees (Goldmann I-V), white stimulus colour, $0-20 \mathrm{~dB}$ dynamic range. Sensitivity was measured across a 45 -point grid centered on the fovea using pattern Macula $12^{\circ}-0 \mathrm{~dB}$. At each point in the grid, sensitivity was measured for a white stimulus 0.438 in diameter (Goldmann size III) presented for $200 \mathrm{~ms}$ against a mesopic background $\left(1.27 \mathrm{~cd} / \mathrm{m}^{2}\right)$. Threshold at each point was determined by using a 4-2 staircase. The "follow-up" feature of MP-1 was used to enable sensitivity measurements at the same retinal locations across all visits. Mean macular sensitivity (MS), the mean of all 45 loci in the central $12^{\circ}\left(1^{\circ}=300 \mu \mathrm{m}\right)$, and mean central macular sensitivity (CMS), the mean sensitivity of the central 13 loci (enclosed by a circle with a $4^{\circ}$ diameter) were recorded. Fixation stability was recorded using MP-1 during the light sensitivity examination. The bivariate contour ellipse area (BCEA) values have been applied to obtain a quantitative measure of fixation stability [31]. We analysed BCEA which contains 68\%, 95\% and $99 \%$ of fixation points. We performed Spectral Domain OCT (RTVue ${ }^{\mathrm{TM}}$ Optovue, Inc, Fremont, CA, USA) using MM6 $(6 \mathrm{~mm} \times 6 \mathrm{~mm})$ scans and Cross Line HD (8 mm length) scans through the macula. Size of LMH was measured using the calliper function in the 'retinal thickness analysis' mode in the Optovue software. Macular hole closure rate was evaluated, defining hole closure as the flattening of macular hole with resolution of the subretinal cuff of fluid and neurosensory retina completely covering the fovea, confirmed by OCT scans. We investigated all patients before surgery and at month $1,3,6,12$ after surgery recording the values of those above parameters. After the purpose and procedures of the operation were explained, informed consent was obtained from all patients. All surgeries were performed under a retrobulbar block (a mixture of $2 \%$ Lidocaina and $2 \%$ Mepivacaina), using the Constellation vitrectomy system (Alcon, Fort Worth, TX, USA). Phacoemulsification was performed in all phakic eyes. All patients included in the study underwent 27-gauge transconjuctival sutureless vitrectomy with posterior hyaloid detachment. Then Brilliant blue G was used to stain ILM in the macula area. ILM peeling with inverted ILM-flap technique was adopted. The ILM peeling was done using pinch and grasp technique up to approximately 2 disc diameters around the macular hole. The edges of the ILM were trimmed with cutter and the remnant was then inverted to cover the macular hole. We lowered the perfusion pressure when inverting the flap and during air-fluid exchange. Gas tamponade with 22\% SF6 was performed, and patients were instructed to remain in prone face 
positioning for 3 days postoperatively. The study followed the tenets of the Declaration of Helsinki and was approved by the institution's review board.

Statistical analysis Statistical analysis was based on all patients included in the study. No formal sample size calculation was performed. Mean and standard deviations were used for continuous variables. A $t$ test was performed on the changes from baseline in BCVA, MS, CMS and BCEA. All statistical tests were performed at the $\mathrm{p}<0.05$ significance level. Simple linear regression model was performed to assess the relationship between BCVA at 12 months and each indipendent variable. The independent variables included age, sex, lens status, axial length, baseline macular hole size, baseline BCVA, MS, CMS, and BCEA 68\%, 95\% and 99\%. Multiple linear regression model in backward with stepwise method was performed to assess any predictive factors associated with postoperative visual acuity at 12 months (cut-off removal variable, $\mathrm{p} \geq 0.10$ ). The factors with a $\mathrm{p}$ value $<0.05$ in the multiple model were considered as potential baseline predictors. Statistical analysis was made using STATA 12.1 Statistical Software (StataCorp), 2014, release 12 (College Station, TX).

\section{Results}

Population's characteristics are summarized in Table 1. A total of 23 eyes of 22 patients were included in this study. The mean age at surgery was $65.6 \pm 5.7$ years. Mean axial length was $23.32 \pm 1.05 \mathrm{~mm}$. Macular hole minimum diameter ranged from $402 \mu \mathrm{m}$ to $1000 \mu \mathrm{m}$. All patients underwent 27-gauge vitrectomy with inverted ILM-flap technique and gas tamponade. The mean BCVA improved significantly from $20 / 230$ (logMar, $1.06 \pm 0.34$ ) to $20 / 81(\log M a r, 0.61 \pm 0.41)$ at 1 month $(\mathrm{p}<0.001)$, 20/62 (logMar, $0.49 \pm 0.42)$ at 3 months $(\mathrm{p}<0.001), 20 / 60$ (logMar, $0.48 \pm 0.43)$ at 6 months $(\mathrm{p}<0.001)$, and $20 / 59$ (logMar, $0.47 \pm 0.45)$ at 12 months $(\mathrm{p}<0.001)$ (Fig. 1$)$. The mean MS improved from $11.30 \pm 4.17 \mathrm{~dB}$ at baseline to $12.08 \pm 4.11 \mathrm{~dB}$ at 1 month ( $\mathrm{p}>0.05$ ), $12.35 \pm 4.18 \mathrm{~dB}$ at 3 months $(\mathrm{p}>0.05), 12.49 \pm 4.23 \mathrm{~dB}$ at 6 months $(\mathrm{p}=0.02)$, and $12.93 \pm 4.38 \mathrm{~dB}$ at 12 months $(\mathrm{p}=0.001)$ (Fig. 2). The mean CMS improved from $6.85 \pm 3.87 \mathrm{~dB}$ at baseline to $8.70 \pm 4.38 \mathrm{~dB}$ at 1 month $(\mathrm{p}=0.03)$, $10.05 \pm 4.86 \mathrm{~dB}$ at 3 months $(\mathrm{p}=0.001), 11.09 \pm 4.61 \mathrm{~dB}$ at 6 months $(\mathrm{p}<0.001)$, and $11.74 \pm 4.90 \mathrm{~dB}$ at 12 months $(\mathrm{p}<0.001)$ (Fig. 3). BCEA changes at three different ellipses area which contain $68 \%, 95 \%$ and $99 \%$ of fixation points, significantly decreased at all follow-up (Table 2, Fig. 4). Simple linear regression analysis showed a significant relationship with each functional baseline parameter and last visual acuity. Multiple linear regression model on all variables together and a multiple linear regression model in backward with stepwise method
Table 1 Baseline characteristics of patients $(n=22)$ and eyes $(n=23)$ underwent surgery

\begin{tabular}{|c|c|}
\hline \multicolumn{2}{|l|}{ Age, years } \\
\hline Mean ( \pm SD) & $65.6 \pm 5.7$ \\
\hline Range & $51-72$ \\
\hline Male: female & $12: 10$ \\
\hline \multicolumn{2}{|l|}{ Axial length, mm } \\
\hline Mean $( \pm S D)$ & $23.32 \pm 1.05$ \\
\hline Range & $21.12-24.60$ \\
\hline Lens status (phakic/pseudophakic) & 9:14 \\
\hline \multicolumn{2}{|l|}{ MH size, $\mu \mathrm{m}$} \\
\hline Mean ( \pm SD) & $511 \pm 129$ \\
\hline Range & $402-1000$ \\
\hline $\mathrm{IOP}(\mathrm{mmHg})$ & $14 \pm 8$ \\
\hline \multicolumn{2}{|l|}{ Baseline mean BCVA, Logmar } \\
\hline Mean $( \pm S D)$ & $1.06 \pm 0.34$ \\
\hline Range & $2.0-0.2$ \\
\hline \multicolumn{2}{|l|}{$M S, d B$} \\
\hline Mean ( \pm SD) & $11.30 \pm 4.17$ \\
\hline Range & $0.6-15.8$ \\
\hline \multicolumn{2}{|l|}{$C M S, d B$} \\
\hline Mean $( \pm S D)$ & $6.85 \pm 3.87$ \\
\hline Range & $0-12.8$ \\
\hline \multicolumn{2}{|l|}{$\begin{array}{l}\text { BCEA, degree }{ }^{2} \\
\text { Mean }( \pm S D)\end{array}$} \\
\hline At $68 \%$ & $5.10 \pm 3.58$ \\
\hline At $95 \%$ & $12.66 \pm 8.60$ \\
\hline At $99 \%$ & $22.68 \pm 16.04$ \\
\hline
\end{tabular}

$S D$ standard deviation, $M H$ macular hole, $I O P$ intraocular pressure, $B C V A$ best corrected visual acuity, logMAR logarithm of minimum angle of resolution, $M S$ macular sensitivity, $d B$ decibel, $C M S$ central macular sensitivity, $B C E A$ biavariate contour ellipse area

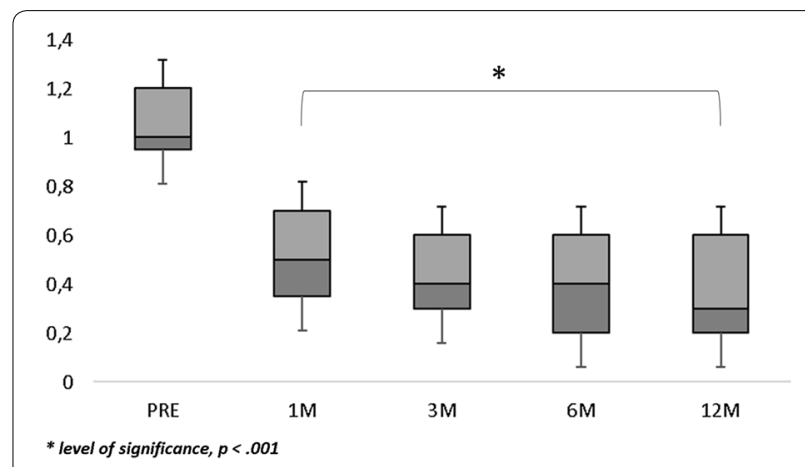

Fig. 1 Visual acuity changes over follow-up. Visual acuity (Logmar) significantly improved after Internal Limiting Membrane (ILM)-flap inversion. Major visual acuity improvement was achieved at 1 and 3 months after surgery with a mild gain at 6 and 12 months

revealed independent associations of baseline MS, BCEA at $95 \%$ and $99 \%$, and macular hole size with final BCVA (Table 3). Mean IOP values were within normal range 

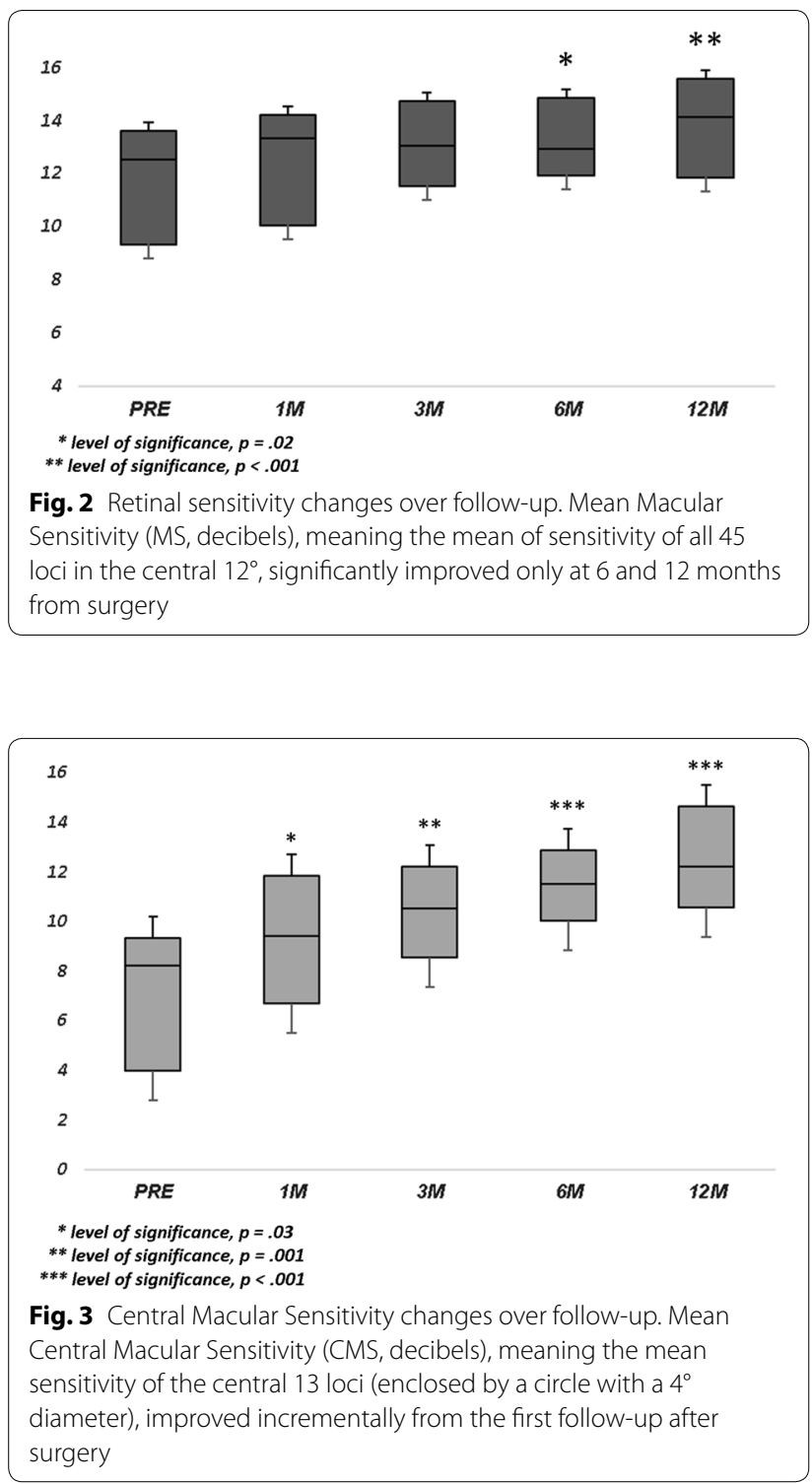

at baseline and at all post-surgery time points. Ocular hypertension $(28 \mathrm{mmHg})$ was observed in only one patient 10 days after surgery. This condition was well controlled with local therapy (dorzolamide/timolol fixed combination 2 times/day). No other ocular or systemic complications were observed. A representative case is shown in Fig. 5.

\section{Discussion}

The inverted ILM-Flap technique has been reported to have a high closure rate of LMH [7-11]. The ILM-flap might work as a scaffold for the proliferation and migration of activated Müller cells that promote the closure of macular hole producing neurotrophic factors [32]. This technique leads to an acceleration of the wound healing processes at the macula. We reported a high anatomical closure rate of $98 \%$, in line with previous reports. In our experience, we found that some modifications of this technique, as lowering the perfusion pressure when inverting the flap and during air-fluid exchange, and the use of gas tamponade might help to avoid the dislocation of the ILM-flap during and after surgery increasing the closure rate, as confirmed by the results of previous papers $[7,8,10-13]$. The influence of flap inversion on functional recovery has been analysed in several papers to understand whether visual prognosis is affected by the presence of the flap over the hole. Indeed, the flap, working as a scaffold and basement membrane for tissue proliferation, should provide an environment to instruct the photoreceptors to assume correct position during the reconstruction process and finally to improve the postoperative visual acuity [9]. In line with previous studies, we found that postoperative visual acuity significantly improves after ILM-flap inversion [7-12]. In particular, major visual acuity improvement was achieved as early as one and 3 months after surgery, and no patients had clinically significant visual acuity improvement beyond this period. This trend in visual improvement could be achieved regardless the recovery of outer retinal layers at the foveal site that would seem occur after at least 3 months from surgery [33]. To date there are no definite conclusions on the role of inverted ILM-flap technique on the outer retinal layers changes and we did not analyse this point. However, our visual outcomes could be explained by the integrity of the detached photoreceptor layer in the perifoveal area or at the edges of the hole, and by the choice to cover rather than to fill the hole with the ILM-flap to avoid that glial tissue proliferation may mechanically obstruct the recovery of outer retinal layers, as previously suggested [34]. However, the functional effects of LMH and surgical technique could be underestimate by BCVA changes so microperimetry, a point to point measurement of retinal sensitivity, may better

Table 2 Changes of fixation quantitative parameter as Bivariate Contour Ellipse Area (BCEA, degree ${ }^{2}$ ) which contains $68 \%, 95 \%$ and $99 \%$ of fixation points

\begin{tabular}{lcccr}
\hline & Baseline & 1 month & 3 months & 12 months \\
\hline BCEA 68\%, degree $^{2}$ & $5.10 \pm 3.58$ & $3.37 \pm 2.32$ & $3.22 \pm 2.74$ & $3.40 \pm 2.94$ \\
BCEA 95\%, degree $^{2}$ & $12.66 \pm 8.60$ & $8.47 \pm 5.36$ & $8.28 \pm 6.64$ & $3.20 \pm 2.97$ \\
BCEA 99\%, degree $^{2}$ & $22.68 \pm 16.04$ & $14.83 \pm 9.00$ & $14.36 \pm 11.58$ & $7.68 \pm 5.68$ \\
\hline
\end{tabular}




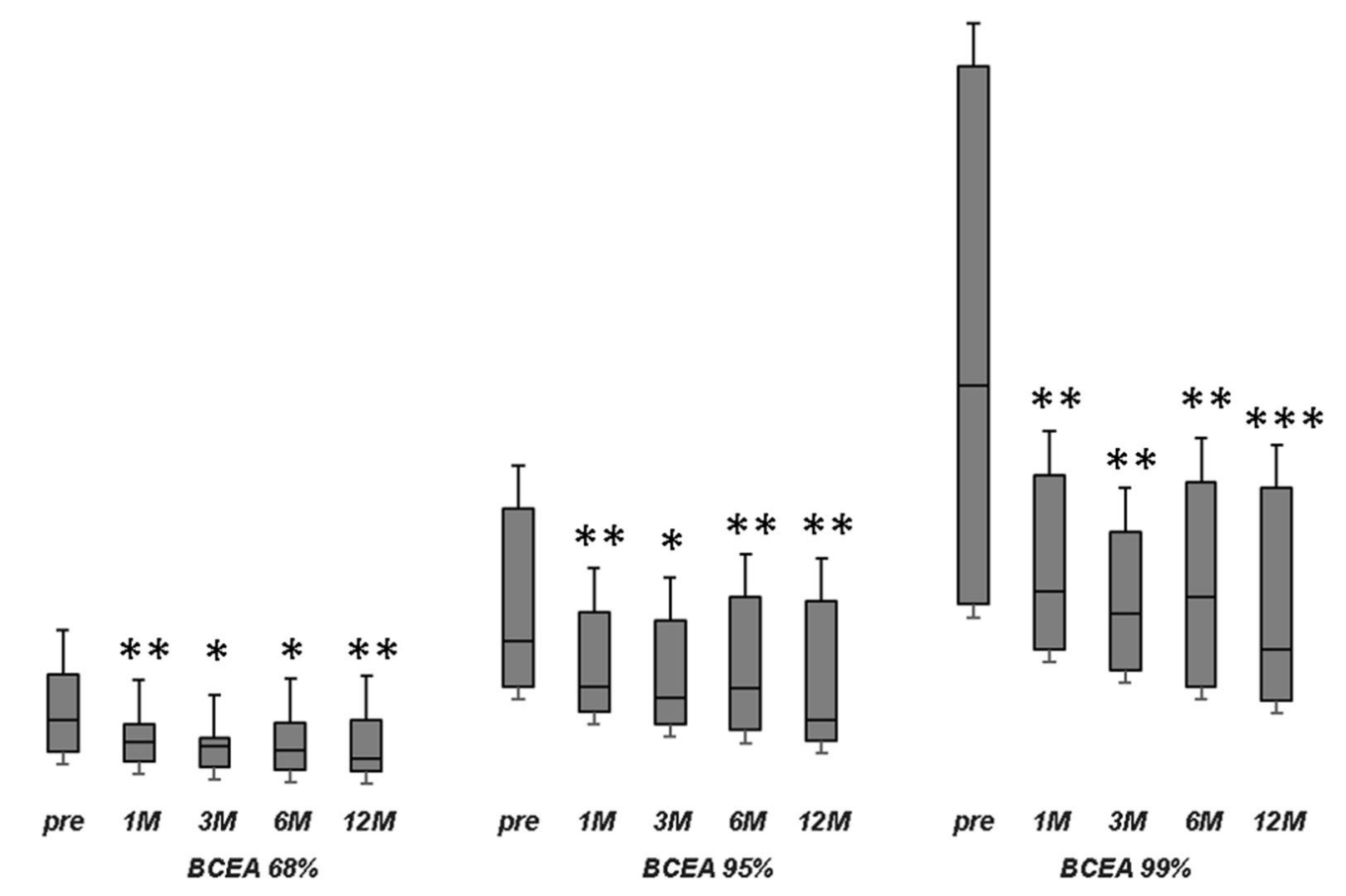

\footnotetext{
* Ievel of significance, $p<.05$

** level of significance, $p \leq .01$

*** Ievel of significance, $p=.001$
}

Fig. 4 Fixation stability changes. The Bivariate Contour Ellipse Area (BCEA) values have been applied to obtain a quantitative measure of fixation stability. We analysed BCEA which contains $68 \%, 95 \%$ and $99 \%$ of fixation points. BCEA significantly decreased at all follow-up

reflect the functional status and recovery after the hole has been repaired [23-26, 28, 35]. In this study, we recorded retinal sensitivity and fixation behavior as BCEA, before and after inverted ILM-flap technique for LMH over one-year follow-up. We analysed the changes in MS, which represents the general sensitivity within the central $12^{\circ}$, and CMS, indicating the retinal sensitivity within the central $4^{\circ}$ of the macula. Previous studies suggested the necessity of investigating MS and CMS separately when evaluating central retinal sensitivity, considering that the sensitivity of the parafoveal retina area is higher than that at the central $0^{\circ}$ in normal individuals, in part explained by the "masking effect" caused by the fixation target during examination [36, 37], and the age-related decrease of sensitivity in the perifoveal area than in the center of macula [38]. Moreover, our aim was to evaluate functional recovery at different retinal sites, at central $4^{\circ}$ (corresponding to an area of $1200 \mu \mathrm{m}$ in diameter at the foveal site) where the gliosis process, promoted by the inverted ILM-flap and controlled by Müller cells, could influence inner and outer retinal layers integrity with functional effects $[9,39,40]$, and at central $12^{\circ}$ where ILM peeling, inducing a temporary swelling of the arcuate nerve fiber layer (SANFL) as the earliest manifestation of dissociated nerve fiber layer (DONFL), leads to a reduced retinal sensitivity and paracentral scotomata in the peeled area [41]. At baseline, microperimetry demonstrated a lower sensitivity at central $4^{\circ}$ (CMS) revealing an absolute scotoma, which corresponds to the neurosensory defect, with surrounding higher sensitivity at $12^{\circ}$ (MS) defining a concentric relative scotoma in the region of the retina around the hole [42]. Our results showed that both CMS and MS significantly improved after surgery. CMS improved incrementally from the first follow-up, mainly at month 1 and 3 after surgery, probably related to the viability of detached photoreceptors at the edges of the hole $[28,29]$. Instead, MS significantly improved only after 6 months from surgery, in particular nine patients showed an early reduction or unchanging of sensitivity at month 1 and 3, probably influenced by early functional damages on inner retinal layers due to ILM peeling, damages that are reversible as confirmed by our results and previous papers $[41,43]$. Furthermore, Baba et al. observed that Brillant blue G-assisted vitrectomy could guarantee a faster restoration of IS/OS junction and a better 
Table 3 Linear regression model of best corrected visual acuity (BCVA) at 12 months on single variables (A); multiple linear regression model on all variables together in the model (B); final multiple linear regression model in backward with stepwise method (C)

\begin{tabular}{|c|c|c|c|c|}
\hline Parameters $^{a}$ & $\beta$ & $\operatorname{se}(\beta)$ & p-value & $95 \% \mathrm{Cl}$ \\
\hline \multicolumn{5}{|l|}{ (A) } \\
\hline Sex (female/male) & -0.32 & 0.18 & 0.09 & -0.70 to 0.05 \\
\hline Lens Status (phakic/pseuphakic) & 0.35 & 0.18 & 0.07 & -0.03 to 0.72 \\
\hline Age & 0.002 & 0.017 & 0.881 & -0.033 to 0.038 \\
\hline $\mathrm{AL}(\mathrm{mm})$ & 0.06 & 0.09 & 0.52 & -0.13 to 0.25 \\
\hline MH size & 0.001 & 0.001 & 0.087 & -0.0002 to 0.0027 \\
\hline BCVA pre (Logmar) & 0.72 & 0.24 & 0.01 & 0.23 to 1.22 \\
\hline MS pre $(\mathrm{dB})$ & -0.067 & 0.017 & 0.001 & -0.102 to -0.032 \\
\hline CMS pre (dB) & -0.06 & 0.02 & 0.01 & -0.10 to -0.01 \\
\hline BCEA $68 \%$ pre & 0.081 & 0.021 & 0.001 & 0.037 to 0.124 \\
\hline BCEA 95\% pre & 0.03 & 0.01 & 0.01 & 0.01 to 0.05 \\
\hline BCEA 99\% pre & 0.014 & 0.005 & 0.016 & 0.003 to 0.025 \\
\hline \multicolumn{5}{|l|}{ (B) } \\
\hline Sex (female/male) & 0.07 & 0.16 & 0.67 & -0.28 to 0.42 \\
\hline LensStatus (Phakic/pseudophakic) & 0.05 & 0.15 & 0.73 & -0.27 to 0.38 \\
\hline Age & 0.004 & 0.011 & 0.69 & -0.019 to 0.003 \\
\hline $\mathrm{AL}(\mathrm{mm})$ & -0.07 & 0.07 & 0.43 & -0.22 to 0.08 \\
\hline MH size & 0.002 & 0.001 & 0.038 & 0.0001 to 000044 \\
\hline BCVA pre (Logmar) & 0.26 & 0.27 & 0.35 & 0.335 to 0.862 \\
\hline MS pre $(\mathrm{dB})$ & -0.085 & 0.231 & 0.004 & -0.136 to 0.034 \\
\hline CMS pre $(\mathrm{dB})$ & 0.05 & 0.03 & 0.12 & -0.01 to 0.11 \\
\hline BCEA 68\% pre & 0.07 & 0.03 & 0.07 & -0.01 to 0.14 \\
\hline BCEA 95\% pre & -0.12 & 0.04 & 0.02 & -0.22 to 0.02 \\
\hline BCEA 99\% pre & 0.06 & 0.02 & 0.03 & 0.01 to 0.11 \\
\hline \multicolumn{5}{|l|}{ (C) } \\
\hline MH size & 0.002 & 0.001 & 0.029 & 0.0002 to 0.0036 \\
\hline MS pre (dB) & -0.056 & 0.013 & 0.001 & -0.084 to -0.028 \\
\hline BCEA $68 \%$ pre & 0.05 & 0.03 & 0.10 & 0.01 to 0.11 \\
\hline BCEA 95\% pre & -0.11 & 0.04 & 0.01 & -0.20 to -0.03 \\
\hline BCEA 99\% pre & 0.06 & 0.02 & 0.01 & 0.02 to 0.11 \\
\hline
\end{tabular}

$\beta$ coefficient, se( $\beta$ ) standard error of coefficient, $A L$ axial length, $M H$ macular hole, $B C V A$ pre best corrected visual acuity preoperative, Logmar logarithm of minimum angle of resolution, $M S$ pre retinal sensitivity preoperative, $d B$ decibel, $C M S$ pre central macular sensitivity preoperative, $B C E A 68 \%, 95 \%, 99 \%$ bivariate contour ellipse area at $68 \%, 95 \%$, and $99 \%$ of fixation points, respectively

a All variables included in the model were considered as continuous

\section{(See figure on next page.)}

Fig. 5 Representative case of inverted Internal Limiting Membrane (ILM)-flap technique for large macular hole (LMH). Morphologic and functional changes over follow-up. OCT scans show the resolution of macular hole over follow-up (left column). Preoperative minimum macular hole diameter was $464 \mu \mathrm{m}$ (left column, top panel). One month after surgery, the LMH was closed and the inverted ILM-flap could be seen covering the hole with a hyperreflective tissue inside the hole (left column, second row panel). Six months postoperatively, outer retinal layers were partially restored (left column, third row panel). Twelve months postoperatively, outer retinal layers were not completely restored (left column, bottom panel). Related microperimetric maps with Bivariate Contour Ellipse Area (BCEA) analysis over follow-up (right column). At baseline, microperimetry revealed an absolute scotoma (red/orange points with low sensitivity values) with a surrounding relative scotoma (yellow points) in the central degrees; BCEA (concentric ellipses) was large in diameter (right column, top panel). One month after surgery, both absolute and relative scotoma progressively reduced with a mild increase of whole sensitivity; BCEA showed a reduction in dimension (right column, second row panel). Six months postoperatively, all retinal sensitivity increased mainly on central degrees; BCEA had a mild increase in dimension (right column, third row panel). At last follow-up, we observed a mild reduction in central retinal sensitivity with a reduction of BCEA (right column, bottom panel) 


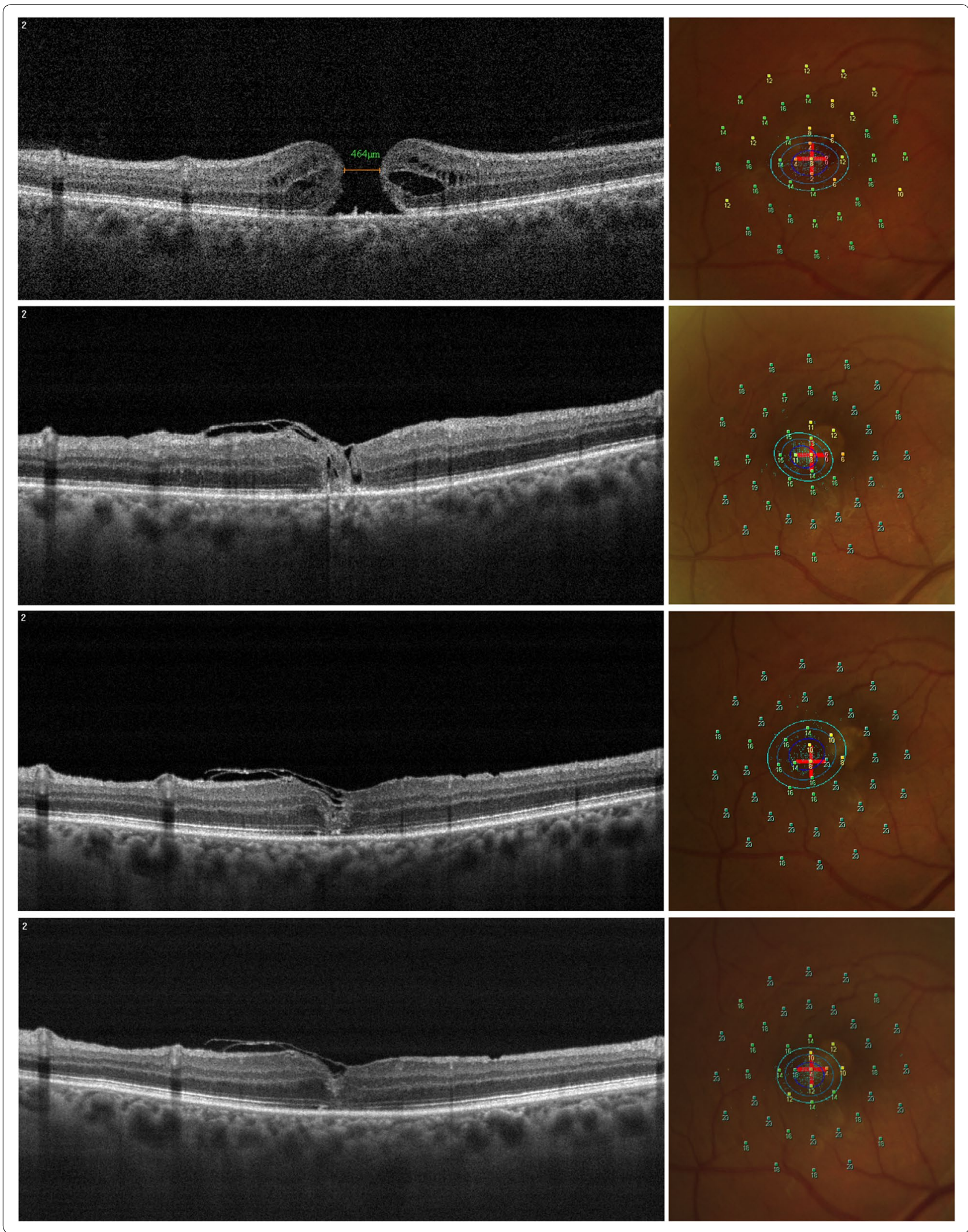


postoperative BCVA and retinal sensitivity in the central degrees [44]. Fixation stability is another important functional parameter to consider in the treatment of macular diseases, probably more than fixation location in macular hole condition where the locus of fixation could already be naturally relocated out of the foveal site. We analysed the effect of inverted ILM-flap on a quantitative parameter of fixation behavior, as BCEA. In our series BCEA improvement had a similar trend at $68 \%, 95 \%$ and $99 \%$ of fixation points at all follow-up. We observed a reduction in dimension of the cloud of the fixation points at month 1 and 3, followed by a mild increase at 6 months and a new mild reduction of all ellipses after 12 months. TaritaNistor et al. reported the same improvement in fixation stability (BCEA) at 1 and 3 months after traditional ILM peeling [27]. As they suggested, the closure of the macular hole could lead to a complex reorganization of fixation behavior. Moreover, we can argue that changes in fixation stability would occur regardless the surgical technique used. In our experience, preoperative functional parameters evaluated as BCVA, MS, CMS and BCEA were individually correlated with final visual acuity. After that, a multiple stepwise linear regression analysis revealed that preoperative MS, BCEA at $95 \%$ and $99 \%$ of the fixation points and macular hole size have a predictive role on final visual acuity at 12 months. We suggest that MS has a significant influence on postsurgical visual acuity, probably because the inverted ILM-flap technique not always leads to photoreceptor reconstitution, and retinal sensitivity at $12^{\circ}(\mathrm{MS})$ is less influenced by foveal microstructure recovery after macular hole closure than CMS at central $4^{\circ}$. The predictive role of a quantitative parameter of fixation behavior as BCEA on postsurgical visual acuity was already reported [27, 30], confirming that a smaller ellipsoid area correlates to more stable fixation and better visual performance. Also macular hole size was revealed as an independent factor predicting 12-month postoperative BCVA. Ota et al. observed the same predictive role of hole diameter for 6-month visual acuity in patients underwent different surgical techniques for LMH [45]. This could be because the recovery in foveal structure after inverted ILM-flap not always correspond to a complete reconstitution of outer retinal layers, not differently from traditional ILM peeling $[45,46]$. Limitations of the study include the small sample size, the absence of a control group, the absence of analysis of outer retinal layers features at OCT scans related to functional changes, and the measurement error or intrinsic variability of microperimetric test. Factors acting on test variability are related to patient's compliance and its anatomical and functional condition, and to the examiner and/or instrument. About patient condition, it should be mentioned the "learning factor" which can justify a certain degree of improvement during follow-up. Regards to the instrument, it should be mentioned the eye-tracker system, not able to ensure the same accuracy of analysis between the posterior pole and peripheral retina, the "point to point" overlapping error $\left(0.5^{\circ}\right.$ to $\left.2^{\circ}\right)$ when "Follow-up" program is used, the "4-2 strategy" which can extend the duration of the test, the "ceeling effect" of MP-1, meaning the tendency to accumulate responses at the highest limit of the sensitivity threshold, and thesize of the given stimulus (Goldmann III, $4 \mathrm{~mm}^{2}$ area, 26 min diameter of arc, or $0.4^{\circ}$ ) that, because of "spatial summation", involves more photoreceptors which converge centrally on a single ganglional cell. As points of strength of this study we highlight the prospective nature of the study, the long term follow-up of 12 months and to our knowledge, the first microperimetric analysis of inverted ILM-flap technique involving different functional parameters.

\section{Conclusions}

High closure rate and visual acuity improvement supported the effectiveness of the inverted ILM-flap technique for LMH. Macular sensitivity at central $12^{\circ}$ and fixation analysis, detectable by microperimetry, give new informations on functional recovery, also revealing their predictive role on visual acuity after inverted ILM-flap technique.

\section{Acknowledgements \\ Not applicable. \\ Authors' contributions \\ GS, AN: Conception and design, Analysis and interpretation of data, draft of the article. VA, TT, VP: Acquisition of data. AS, LS, RD, EG: Analysis and interpre- tation of data. NR, FB, GA: Final approval of the version to be published. All authors read and approved the final manuscript.}

\section{Funding}

There is no financial support for this study.

\section{Availability of data and materials}

The datasets during and/or analysed during the current study available from the corresponding author on reasonable request.

\section{Ethics approval and consent to participate}

The study was performed in accordance with the Declaration of Helsinki and approved by the institution's review board. Each patient signed the informed consent form.

\section{Consent for publication}

Written informed consent was obtained for publication of this study.

\section{Competing interests}

The authors declare that they have no competing interests.

\section{Author details}

1 Department of Medical Science, Neuroscience and Sense Organs, Eye Clinic, University of Bari, Bari, Italy. ${ }^{2}$ Eye Clinic, Hospital "S. G. MOSCATI", ASL TA, Via Per Martina Franca, 74010 Statte, Taranto, Italy. ${ }^{3}$ National Institute of Gastroenterology "S. de Bellis" Research Hospital, Castellana Grotte, Bari, Italy. ${ }^{4}$ Department of Surgical, Microsurgical and Medical Sciences, Eye Clinic, University of Sassari, Sassari, Italy. 
Received: 5 July 2019 Accepted: 10 October 2019

Published online: 18 October 2019

\section{References}

1. Gass JD. Idiopathic senile macular hole Its early stages and pathogenesis. Arch Ophthalmol. 1988;106:629-39. https://doi.org/10.1001/archo pht.1988.01060130683026.

2. Beutel J, Dahmen G, Ziegler A, Hoerauf H. Internal limiting membrane peeling with indocyanine green or trypan blue in macular hole surgery: a randomized trial. Arch Ophthalmol. 2007;125(3):326-32. https://doi. org/10.1001/archopht.125.3.326.

3. Lois N, Burr J, Norrie J, et al. Internal limiting membrane peeling versus no peeling for idiopathic full-thickness macular hole: a pragmatic randomized controlled trial Group. Invest Ophthalmol Vis Sci. 2011;52(3):1586-92. https://doi.org/10.1167/iovs.10-6287.

4. Morescalchi F, Costagliola C, Gambicorti E, et al. Controversies over the role of internal limiting membrane peeling during vitrectomy in macular hole surgery. Surv Ophthalmol. 2017;62(1):58-69. https://doi. org/10.1016/j.survophthal.2016.07.003.

5. Cornish $\mathrm{K}$, Lois N, Scott N, et al. Vitrectomy with internal limiting membrane (ILM) peeling versus vitrectomy with no peeling for idiopathic full-thickness macular hole (FTMH). Cochrane Database Syst Rev. 2013;6:009306. https://doi.org/10.1002/14651858.CD009306.pub2.

6. Rahimy E, Cannel CA. Impact of internal limiting membrane peeling on macular hole reopening. A systematic review and meta-analysis. Retina. 2016;36:679-87. https://doi.org/10.1097/IAE.0000000000000782.

7. Velez-Montoya R, Ramirez-Estudillo JA, Liano C, et al. Inverted ILM flap, free ILM flap and conventional ILM peeling for large macular holes. Int J Retina Vitreous. 2018;4:8. https://doi.org/10.1186/s40942-018-0111-5.

8. Narayanan R, Singh SR, Taylor S, et al. Surgical outcomes after inverted internal limiting membrane flap versus conventional peeling for very large macular holes. Retina. 2019;39(8):1465-9. https://doi.org/10.1097/ IAE.0000000000002186.

9. Michalewska Z, Michalewski J, Adelman RA, Nawrocki J. Inverted internal limiting membrane flap technique for large macular holes. Ophthalmology. 2010;117:2018-25. https://doi.org/10.1016/j.ophtha.2010.02.011.

10. Gu C, Qiu Q. Inverted internal limiting membrane flap technique for large macular holes: a systematic review and single-arm meta-analysis. Graefes Arch Clin Exp Ophthalmol. 2018;256(6):1041-9. https://doi.org/10.1007/ s00417-018-3956-2.

11. Manasa S, Kakkar P, Kumar A, et al. Comparative evaluation of standard ILM peel with inverted ILM flap technique in large macular holes: a prospective, randomized study. Ophthalmic Surg Lasers Imaging Retina. 2018:49:236-40. https://doi.org/10.3928/23258160-20180329-04.

12. Rizzo S, Tartaro R, Barca F, et al. Internal limiting membrane peeling versus inverted flap technique for treatment of full-thickness macular holes: a comparative study in a large series of patients. Retina. 2017;38(1):73-8. https://doi.org/10.1097/IAE.0000000000001985.

13. Kannan NB, Kohli P, Parida H, et al. Comparative study of inverted internal limiting membrane (ILM) flap and ILM peeling technique in large macular holes: a randomized-control trial. BMC Ophthalmol. 2018;18(1):177. https ://doi.org/10.1186/s12886-018-0826-y.

14. Squirrell $D$, Ehrlich $R$. The use of macular microperimetry in the assessment and diagnosis of macular disease. Retinal Physician. 2012;9:53-7.

15. Chen FK, Patel PJ, Xing W, et al. Test-retest variability of microperimetry using the nidek MP1 in patients with macular disease. Invest Ophthalmol Vis Sci. 2009:50(7):3464-72. https://doi.org/10.1167/iovs.08-2926.

16. Wong EN, Chew AL, Morgan WH, et al. The use of microperimetry to detect functional progression in non-neovascular age-related macular degeneration: a systematic review. Asia Pac J Ophthalmol. 2017;6(1):70-9. https://doi.org/10.22608/APO.201643.

17. Vujosevic S, Torresin T, Berton M, et al. Diabetic macular edema with and without subfoveal neuroretinal detachment: two different morphologic and functional entities. Am J Ophthalmol. 2017;181:149-55. https://doi. org/10.1016/j.ajo.2017.06.026.

18. Niro A, Sborgia G, Sborgia A, et al. Analysis of morphologic and functional outcomes in macular edema due to central retinal vein occlusion treated with intravitreal dexamethasone implant. J Ophthalmol. 2018;2018:5604632. https://doi.org/10.1155/2018/5604632.
19. Dal Vecchio M, Lavia C, Nassisi M, et al. Microperimetric assessment after epiretinal membrane study: 4 year follow-up. J Ophthalmol. 2016;2016:7030791. https://doi.org/10.1155/2016/7030791.

20. Ozdemir H, Senturk F, Karacorlu M, et al. Macular sensitivity in eyes with central serous chorioretinopathy. Eur J Ophthalmol. 2008;18(5):799-804 https://doi.org/10.1177/112067210801800522.

21. Munk MR, Kiss CG, HufW, et al. Visual acuity and microperimetric mapping of lesion area in eyes with inflammatory cystoid macular oedema. Acta Ophthalmol. 2014;92:332-8. https://doi.org/10.1111/aos.12201.

22. Testa F, Melillo P, Lorio VD, et al. Macular function and morphological features in juvenile Stargardt dsease: longitudinal study. Ophthalmology. 2014;121(2):2399-405. https://doi.org/10.1016/j.ophtha.2014.06.032.

23. Amari F, Ohta K, Kojima H, Yoshimura N. Predicting visual outcome after macular hole surgery using scanning laser ophthalmoscope microperimetry. Br J Ophthalmol. 2001;85(1):96-8. https://doi.org/10.1136/ bjo.85.1.96.

24. Chen WC, Wang Y, Li XX. Morphologic and functional evaluation before and after successful macular hole surgery using spectral-domain optical coherence tomography combined with microperimetry. Retina. 2012;32(9):1733-42. https://doi.org/10.1097//AE.0b013e318242b81a.

25. Cappello E, Virgili G, Tollot L, et al. Reading ability and retinal sensitivity after surgery for macular hole and macular pucker. Retina. 2009;29(8):1111-8. https://doi.org/10.1097/IAE.0b013e3181a3b832.

26. Ozdemir H, Karacorlu M, Senturk F, et al. Retinal sensitivity and fixation changes 1 year after triamcinolone acetonide assisted internal limiting membrane peeling for macular hole surgery: a MP-1 microperimetric study. Acta Ophthalmol. 2010;88(6):e222-7. https://doi.org/10.111 1/j.1755-3768.2010.01898.x.

27. Tarita-Nistor L, González EG, Mandelcorn MS, et al. Fixation stability, fixation location, and visual acuity after successful macular hole surgery. Invest Ophthalmol Vis Sci. 2009;50(1):84-9. https://doi.org/10.1167/ jovs.08-2342.

28. Bonnabel A, Bron AM, Isaico R, et al. Long-term anatomical and functional outcomes of idiopathic macular hole surgery The yield of spectraldomain OCT combined with microperimetry. Graefes Arch Clin Exp Ophthalmol. 2013;251(11):2505-11. https://doi.org/10.1007/s0041 7-013-2339-y.

29. Chung SE, Lim DH, Kang SW, et al. Central photoreceptor viability and prediction of visual outcome in patients with idiopathic macular holes. Korean J Ophthalmol. 2010;24(4):213-8. https://doi.org/10.3341/ kjo.2010.24.4.213

30. Sun Z, Gan D, Jiang C, et al. Effect of preoperative retinal sensitivity and fixation on long-term prognosis for idiopathic macular holes. Graefes Arch Clin Exp Ophthalmol. 2012;250(11):1587-96. https://doi. org/10.1007/s00417-012-1997-5.

31. Castet $\mathrm{E}$, Crossland M. Quantifying eye stability during a fixation task: a review of definitions and methods. Seeing Perceiving. 2012;25(5):449-69. https://doi.org/10.1163/187847611X620955.

32. Shiode $Y$, Morizane $Y$, Matoba $R$, et al. The role of inverted internal limiting membrane flap in macular hole closure. Invest Ophthalmol Vis Sci. 2017:58:4847-55. https://doi.org/10.1167/iovs.17-21756.

33. Kase S, Saito W, Mori S, et al. Clinical and histological evaluation of large macular hole surgery using the inverted internal limiting membrane flap technique. Clin Ophthalmol. 2016;11:9-14. https://doi.org/10.2147/OPTH. S119762.

34. Iwasaki M, Kinoshita T, Miyamoto $H$, Imaizumi $H$. Influence of inverted internal limiting membrane flap technique on the outer retinal layer structures after a large macular hole surgery. Retina. 2019;39(8):1470-7. https://doi.org/10.1097//AE.0000000000002209.

35. Richter-Mueksch S, Vécsei-Marlovits PV, Sacu SG, et al. Functional macular mapping in patients with vitreomacular pathologic features before and after surgery. Am J Ophthalmol. 2007;144(1):23-31. https://doi. org/10.1016/j.ajo.2007.03.045.

36. Fujiwara A, Shiragami C, Manabe S, et al. Normal values of retinal sensitivity determined by macular integrity assessment. Nippon Ganka Gakkai zasshi. 2014;118(1):15-21.

37. Denniss J, Astle AT. Central perimetric sensitivity estimates are directly influenced by the fixation target. Ophthalmic Physiol Opt. 2016;36(4):453-8. https://doi.org/10.1111/opo.12304.

38. Sabates FN, Vincent RD, Koulen P, et al. Normative data set identifying properties of the macula across age groups: integration of visual 
function and retinal structure with microperimetry and spectral-domain optical coherence tomography. Retina. 2011;31(7):1294-302. https://doi. org/10.1097/IAE.0b013e3182019be2.

39. Michalewska Z, Michalewski J, Dulczewska-Cichecka K, et al. Temporal inverted internal limiting membrane flap technique versus classic inverted internal limiting membrane flap technique: a comparative study. Retina. 2015;35(9):1844-50. https://doi.org/10.1097/IAE.0000000000 000555.

40. Michalewska Z, Michalewski J, Cisiecki S, et al. Correlation between foveal structure and visual outcome following macular hole surgery: a spectral optical coherence tomography study. Graefes Arch Clin Exp Ophthalmol. 2008;246(6):823-30. https://doi.org/10.1007/s00417-007-0764-5.

41. Clark A, Balducci N, Pichi F, et al. Swelling of the arcuate nerve fiber layer after internal limiting membrane peeling. Retina. 2012;32(8):1608-13. https://doi.org/10.1097/IAE.0b013e3182437e86.

42. Sjaarda RN, Frank DA, Glaser BM, et al. Resolution of an absolute scotoma and improvement of relative scotomata after successful macular hole surgery. Am J Ophthalmol. 1993;1 16(2):129-39. https://doi.org/10.1016/ s0002-9394(14)71276-0.

43. Tadayoni R, Svorenova I, Erginay A, et al. Decreased retinal sensitivity after internal limiting membrane peeling for macular hole surgery. Br
J Ophthalmol. 2012;96:1513-6. https://doi.org/10.1136/bjophthalm ol-2012-302035.

44. Baba T, Hagiwara A, Sato E, et al. Comparison of vitrectomy with brilliant blue $\mathrm{G}$ or indocyanine green on retinal microstructure and function of eyes with macular hole. Ophthalmology. 2012;119(12):2609-15. https:// doi.org/10.1016/j.ophtha.2012.06.048.

45. Ota H, Kunikata H, Aizawa N, Nakazawa T. Surgical results of internal limiting membrane flap inversion and internal limiting membrane peeling for macular hole. PLoS ONE. 2018;13(9):e0203789. https://doi.org/10.1371/ journal.pone.0203789.

46. Hayashi H, Kuriyama S. Foveal microstructure in macular holes surgically closed by inverted internal limiting membrane flap technique. Retina. 2014;34(12):2444-50. https://doi.org/10.1097/IAE.0000000000000252.

\section{Publisher's Note}

Springer Nature remains neutral with regard to jurisdictional claims in published maps and institutional affiliations.
Ready to submit your research? Choose BMC and benefit from:

- fast, convenient online submission

- thorough peer review by experienced researchers in your field

- rapid publication on acceptance

- support for research data, including large and complex data types

- gold Open Access which fosters wider collaboration and increased citations

- maximum visibility for your research: over $100 \mathrm{M}$ website views per year

At BMC, research is always in progress.

Learn more biomedcentral.com/submissions 